\title{
Study on Ni/MH Composite Plating and Its Performance for Hydrogen Evolution Reaction
}

\author{
Shouguang Yao ${ }^{1, *}$, Hao $\mathrm{Xu}^{1,2,3}$, Min Xiao $^{1}$, Jie Cheng ${ }^{2,3}$, Yusheng Yang ${ }^{2,3}$ \\ ${ }^{1}$ School of Energy and Power Engineering, Jiangsu University of Science and Technology, Zhenjiang, \\ Jiangsu 212003, China \\ ${ }^{2}$ Zhangjiagang Smartgrid Fanghua electrical energy storage research institute Co. Ltd., Zhangjiagang \\ 215600, China \\ ${ }^{3}$ Chilwee Power Co., Ltd., Huzhou 313100, China \\ *E-mail: zjyaosg@126.com
}

doi: $10.20964 / 2021.05 .62$

Received: 25 January 2021 / Accepted: 11 March 2021 / Published: 31 March 2021

\begin{abstract}
In order to improve the hydrogen evolution stability of nickel electrodes, this paper prepares a composite nickel-plated/hydrogen storage alloy $(\mathrm{Ni} / \mathrm{MH})$ electrode and investigates its hydrogen evolution performance in alkaline aqueous solutions. Characterization results such as scanning electron microscopy (SEM), X-ray diffraction (XRD) and energy dispersive spectrometer (EDS) indicate that the hydrogen storage alloy particles have been uniformly deposited inside and on the surface of the nickel plating, and that pores exist on the electrode surface. The linear sweep voltammetry (LSV) at room temperature shows that the overpotential of the $\mathrm{Ni} / \mathrm{MH}$ composite electrode is $196 \mathrm{mV}$ when the current density reaches $50 \mathrm{~mA} \cdot \mathrm{cm}^{-2}$ and $231 \mathrm{mV}$ when the current density reaches $100 \mathrm{~mA} \cdot \mathrm{cm}^{-2}$. The tafel slope of $100 \mathrm{mV} \cdot \mathrm{dec}^{-1}$, which performs much better than nickel-plated electrodes. Chronopotentiometry (CP) showed that the potential response of the $\mathrm{Ni} / \mathrm{MH}$ composite electrode was very stable and comparable to that of the Pt electrode, while the Ni electrode polarization continued to increase. Electrochemical impedance spectroscopy (EIS) tests confirmed that the $\mathrm{Ni} / \mathrm{MH}$ composite electrode had a low charge transfer resistance. In summary, the results show that composite plating with hydrogen storage alloy significantly improves the hydrogen evolution catalytic performance of nickel electrodes and has a broad application prospect.
\end{abstract}

Keywords: Composite nickel/hydrogen storage alloy electrode; Catalytic activity of hydrogen evolution; Stability; Overpotential

\section{$\underline{\text { FULL TEXT }}$}


(C) 2021 The Authors. Published by ESG (www.electrochemsci.org). This article is an open access article distributed under the terms and conditions of the Creative Commons Attribution license (http://creativecommons.org/licenses/by/4.0/). 